\title{
LA EXTREMADURA \\ CASTELLANO-LEONESA: \\ HACIA LA CONSTRUCCION \\ DE UN MODELO
}

JOSE A. G. DE CORTAZAR

Universidad de Cantabria

Hasta hace cinco años, aproximadamente, nuestro conocimiento sobre la historia medieval del espacio comprendido entre el Duero y el Sistema Central se reducía a unos cuantos trabajos desperdigados cuyo contenido y conclusiones venían a prolongar, apoyando o, como mucho, matizando las tesis de Sánchez Albornoz ${ }^{1}$. Despoblamiento, menos riguroso que al norte del Duero, pero no menos significativo y decisivo, entre los siglos vin y fines del xI. Reconstrucción del espacio económico y de la sociedad sobre la base de poderosos concejos dotados de amplio alfoz, dentro del cual se organiza una comunidad de villa y tierra entre la capital de cada uno de ellos y el conjunto de sus aldeas. Las exigencias de la lucha de frontera, característica de los primeros cien años de la vida de los núcleos de esta Extremadura castellano-leonesa, configuran una sociedad dotada de enorme movilidad social. Cualquier persona presta a combatir es bien recibida. A nadie se pregunta por su pasado mientras sea capaz de sostener caballo y armas. Una verdadera democracia se instala en estos islotes de libertad que son las ciudades de frontera dentro del mar feudal. Sólo a fines del siglo xII comienza a reservarse a los caballeros el control del concejo, aunque únicamente como reconocimiento de la superioridad de su función militar en una época de frecuentes enfrentamientos y continuas amenazas.

Desde hace cinco o seis años, la atención a la Extremadura castellanoleonesa se ha convertido en tema de predilección historiográfica. Desde Salamanca (el grupo de José Luis Martín Rodríguez, en especial, Angel Barrios), Valladolid (por un lado, Gonzalo Martínez; por otro, alguno de los discípulos de Valdeón, como Martínez Moro o Gavilán) y Madrid (con perspectivas distintas entre sí, Santamaría Lancho o Asenjo González), se aborda la historia medieval de esa Extremadura. Y, dentro de ella, se insiste, en amplia cronología, en el tramo segoviano. La segovianitis es, sin duda, un dato llamativo

${ }^{1}$ Véase un estado de la cuestión sobre estos aspectos, anterior a la actual preocupación por la zona, en Salvador DE Moxo, Repoblación y sociedad en la España cristiana medieval, Madrid, Ediciones Rialp, 1979, pp. $42-45$ y 201-216. 
de nuestra más reciente historiografía medieval. De ella participa el libro de Luis Miguel Villar García ${ }^{2}$. Seiscientas páginas para enfrentarse con una región una cronología y un tema que, desde otra óptica que la albornociana, vuelven a demostrar su condición de charnela histórica en nuestro devenir medieval. Esto es, de zona en que se define y cristaliza un modelo concreto de organización, presto para su exportación cuando las victorias del siglo XIII pongan en manos cristianas la mitad sur de la Península.

El modelo ha dejado al norte del Duero dos protagonistas característicos también de la historiografía de los últimos veinte años: los dominios monásticos y las aldeas. Recoge ahora los dos que los van a sustituir: los dominios de los cabildos catedralicios y los concejos urbanos. Y, en su presentación, Villar no se recata de perseguir una estricta simultaneidad en el proceso que lleva a la cristalización de ambas instituciones. En un sentido que, visto desde su conclusión, es el de un reparto de capacidades y competencias entre los caballeros monopolizadores del concejo y el obispo y sus capitulares sobre el resto de la población. No sólo la de las ciudades cabeza de extensos alfoces, en especial, de las que, a la vez, son sede de obispados - Salamanca, Avila, Segovia-, sino, en especial, de la población de campesinos residentes en las numerosas aldeas de la Tierra. A través del ejercicio de tales competencias, caballeros y capitulares van apropiándose de los excedentes del campesinado y materializando e institucionalizando una sociedad feudal, cada vez más rigurosamente jerarquizada, que utiliza el dominio del concejo urbano para normativizar en su provecho. Hacia mediados del siglo xIII, esta sociedad ha cristalizado ya definitivamente y se apresta a vivir un proceso de autorreproducción, en lo posible, ampliada, sobre la base, sobre todo, de los excedentes ganaderos y el control de las actividades mercantiles y artesanales desarrolladas en las localidades más importantes de la Extremadura castellano-leonesa.

Treinta mil kilómetros cuadrados de los obispados de Segovia, Avila y Salamanca constituyen el escenario del estudio. Sobre él, y dejando al margen las cuarenta páginas dedicadas a hipotetizar sobre los destinos de esa región entre 711 y 1085 , en que permaneció más poblada de lo supuesto y con un aprovechamiento ganadero del espacio, Luis Miguel Villar articula su investigación en dos grandes apartados. En el primero, de 1085 a 1157, se viven la colonización y la organización y estructuración social de la Extremadura. Son procesos en que cada «orden» cumple su respectiva función. Los caballeros guerrean y son ganaderos. Los clérigos no guerrean, como sugería Barrios ${ }^{3}$,

${ }^{2}$ Luis Miguel Villar García, La Extremadura castellano-leonesa. Guerreros, clérigos y campesinos (711-1252), Valladolid, Junta de Castilla y León, 1986, 616 pp. El trabajo constituyó su tesis doctoral, que, dirigida por José Luis Martín Rodríguez, defendió el autor en mayo de 1984.

${ }^{3}$ Angel Barrios Garcín, Estructuras agrarias y de poder en Castilla. El ejemplo de 
sino que, imbuidos del espíritu de frontera, animan a los caballeros y, como éstos, se benefician de las dedicaciones ganaderas, aunque sin descuidar un patrimonio agrícola que no hace sino crecer en todo este período y el siguiente. A su cargo, los campesinos. El proceso era conocido, pero, desde el punto de vista del poder y la jurisdicción, el autor ha podido discernir dos fases significativas. Una primera, entre 1085 y 1130 , caracterizada, en el plano que llamaríamos civil, por el poder del rey y sus delegados, y, en el plano de la administración eclesiástica, por el personalismo de los obispos restauradores. Una segunda, entre 1130 y 1157 , caracterizada por el nacimiento de las autoridades concejiles y la adecuación de los representantes reales a ellas, $y$, en el ámbito eclesiástico, por la territorialización y jerarquización administrativa: nacimiento de arcedianatos y parroquias. Este doble proceso se acompaña por un distanciamiento social de los caballeros ganaderos respecto a los campesinos. La guerra lo propicia, al realzar la función guerrera. Distanciamiento que no creación. La discriminación social guerreros/campesinos venía de más atrás de lo que pensaba Angel Barrios. Prácticamente de los momentos iniciales de la repoblación. Llegaba con los repobladores. Objetivo de Villar será, por su parte, presentar como estrictamente paralelos, en cronología y mecanismos, los procesos de constitución de la fuerza social de los caballeros y de los capitulares. Frente a ambos, y pese a una debilidad de datos concretos, su conclusión también es clara: el apesadumbramiento de la presión señorial de aquéllos sobre los campesinos.

La segunda parte del trabajo estudia la consolidación y feudalización de la frontera extremeña entre 1157 y 1250 . A partir de una Extremadura castellana asegurada y poblada y de una leonesa en buena parte despoblada todavía, se va produciendo la colmatación humana de la zona. La creación de los términos de Ciudad Rodrigo y Ledesma y la expansión sudoccidental del de Salamanca son signos de una atribución definitiva del espacio. Su ordenación se hace a través de innumerables lugares de población, de muy distintas dimensiones, con una cierta concentración en las áreas inmediatas a las ciudades y villas. La cristalización de los grandes alfoces concejiles es, a su vez, síntoma y consecuencia de la obligada renuncia a la expansión por la Transierra, frenada por la constitución aquí de otros grandes concejos. Esta situación animará a los caballeros ganaderos de la Extremadura a consolidar definitivamente su hegemonía dentro de sus respectivos concejos, a la vez que tratan de obtener de los campesinos de las aldeas los excedentes que esperaban haber obtenido en su expansión hacia el Sur, ahora interrumpida.

Se incrementa la actividad agrícola, que, por falta de fuentes, el autor ape-

Avila (1085-1320), Salamanca, Ediciones Universidad de Salamanca, Institución Gran Duque de Alba, 1983, 2 vols. 
nas puede reconstruir con una apoyatura en la historiografía general y en los fueros. Y, sobre todo, se ordena la explotación ganadera. En especial la trashumante. En un principio, hacia $1150-1160$, es una trashumancia de variadas especies (ovino, vacuno, porcino) que discurre sin itinerarios reconocidos ni ritmos fijos, apoyándose en los pastos de los propios extensos concejos y en los de los vecinos. Sólo desde los primeros decenios del siglo XIII, la trashumancia regulariza sus recorridos y hace de las ovejas la especie dominante. Por fin, las ganancias de caballeros y clérigos convocan a su alrededor en las ciudades a una población de comerciantes y artesanos dispuestos a satisfacer sus demandas. La amplia diversificación de las ocupaciones artesanales nos deja en la ignorancia más absoluta sobre la importancia respectiva de cada una. En cualquier caso, no parece significativa ninguna de ellas. Al menos, los artesanos no sólo no llegan a adquirir cuotas de poder municipal, sino que, además, el descrédito del menestral en la ideología dominante le obliga a abandonar su oficio si aspira a alcanzar privilegios sociales.

Estos se concretan, ante todo, en la adquisición de la caballería villana, que, a su vez, es, para estas horas, el requisito imprescindible para optar a participar en el gobierno del concejo. Sólo son los caballeros quienes propiamente pueden recibir el título de vecinos y conseguir que los textos forales se pronuncien en su favor. A través de éstos se organizan formas de apropiación de los excedentes agroganaderos y, en definitiva, se ordena la sociedad de la Extremadura. Por debajo de caballeros y clérigos, el amplio sector del campesinado. Campesinos propietarios, vasallos del concejo; campesinosvasallos o solariegos, dependientes de los señores; yugueros, hortelanos, pastores $\mathrm{y}$ otros jornaleros. A través de muy variadas fórmulas, seguidas al hilo de los fueros extensos, los señores se apropian del excedente de sus campesinos. El beneficio de los residentes en la ciudad es tanto mayor cuanto que a alguno de los más significados (obispo y cabildo) llega buena parte del diezmo eclesiástico que todos deben satisfacer. En efecto, la disociación existente entre la parroquia rural, donde radicaban los bienes raíces, y la feligrasía urbana, donde residen sus propietarios, se solventa, en buena parte, en favor de ésta. En consecuencia, merma la parte del diezmo, que, en concepto de fábrica, quedaba en manos de la parroquia rural.

El resultado final es el dominio indiscutible que caballeros y capitulares imponen en la Extremadura castellano-leonesa. Los primeros cierran el paso a quienes no tienen fortuna suficiente para sostener armas y un caballo de una determinada cuantía. Los segundos, a falta de los linajes específicos que comenzarán a consolidar los caballeros, surgirán de ellos $\mathrm{y}$, a través de conexiones familiares, mantendrán una relación permanente con los primeros. Unidos por el parentesco, los grupos dominantes de laicos y eclesiásticos asegurarán su hegemonía. 
Seiscientas páginas nos han conducido a esta conclusión. En cada una de ellas no menos de cuatro erratas tipográficas, y unas cuantas más en la paginación señalada en el Indice. Los veintisiete mapas incluidos en el estudio muestran más pulcritud y una preocupación por el espacio, visible en la trama utilizada en los mismos, que facilita el análisis y la interpretación de los fenómenos. Al acabar la lectura, la admiración por lo redondo del modelo puesto en pie por el autor no cierra el paso a unas cuantas preguntas. La primera se refiere a la propia extensión del estudio. Un adelgazamiento de 150-200 páginas no habría mermado su contenido y habría evitado que la escasez de datos animara, una y otra vez, al autor a reiterar a lo largo del libro sus conclusiones, que son sus premisas. Una sociedad claramente jerarquizada entre señores ganaderos y campesinos agricultores, ya desde su instalación en la zona, que encuentra en las circunstancias vividas por ésta en el siglo xII razón y ocasión para hacer más acusada la disimetría social inicial.

Pero, a falta de datos concretos, ¿cómo valorar ésta? En definitiva, ¿cómo armonizar la «gran masa de jornaleros del campo... [que] uno no dudaría en considerar generalizada su situación a un alto porcentaje de la población extremeña» (p. 505) con «el grupo más numeroso [el de] los campesinos propietarios, vecinos y vasallos del concejo» (p. 507)? Evidentemente, la aplicación de adjetivos de magnitud traiciona al autor, pero, a la vez, confunde al lector. Este, por otra parte, puede que esté ya dispuesto a aceptar como elemento angular de relación entre señores y campesinos la denominada renta feudal, pero, probablemente, echará en falta muchas veces un análisis en que el autor demuestre de hecho la inanidad de la diferencia entre renta territorial y renta jurisdiccional. Aun dando por conocido el destino de ambas y, por tanto, lo limitado de su distinción, mantener ésta, ¿empobrece o, por el contrario, enriquece el modelo?, máxime cuando, en cambio, el diezmo eclesiástico aparece en el estudio con una autonomía que, suponemos, será debida al interés por subrayar el proceso de enriquecimiento del cabildo, paralelo al de los caballeros.

$\mathrm{El}$ control de éstos sobre el concejo urbano parece claro. $\mathrm{O}$, a falta de prosopografías y estudios de linajes, al menos, verosímil. Lo que no es tan claro es el funcionamiento interno del concejo, probablemente por esa oscuridad de las fuentes sobre las personas que ocupan los distintos oficios del mismo. Pero aquélla, acompañada de la reiteración del autor en la premisa de la dominación de los caballeros ganaderos, obliga a una lectura muy atenta para ver las posibilidades de acceso a la caballería villana por parte de gentes inicialmente no ganaderas. Por encima de esas oscuridades, Villar tiene buen cuidado en subrayar cómo el poder de esos caballeros villanos no se ejerce a título individual, sino a través del control colectivo de ese concejo urbano. Pero, en cambio, la ausencia de conclusiones explícitas del libro impide co- 
nocer cómo resuelve Villar la articulación entre la dedicación ganadera de los señores y su tendencia a hacer más pesada su presión sobre el campesinado por medios que parecen habituales en áreas específicamente agrarias. La importancia de la ganadería, no sólo lógica en la zona, sino también instrumento reiteradamente utilizado por el autor para caracterizar la sociedad de la Extremadura, no sabemos cómo acaba entrando en el modelo de sociedad feudal que propone. Es comprensible que la falta de fuentes concretas, en especial en el ámbito de la ganadería, hace difícil trascender el nivel de algunas de sus interesantísimas observaciones. Pero, en esas condiciones, ¿cómo se puede subrayar su importancia?, y, sobre todo, ¿cómo subrayarla y luego no deducir sus consecuencias de la incorporación al modelo?

La pregunta es, por supuesto, más fácil de formular que de responder. El modelo «castellano» de Feudalismo, con inclusión de una importante ganadería, base incluso de la dicotomía social señores/campesinos, apuntada ya hace unos cuantos años, debería dejar ver formas menos onerosas de presión señorial directa que en otros espacios. $Y$, en consecuencia, quizá niveles de señorialización distintos, menos pesados que en otras partes. Naturalmente, no vamos a pedir a Villar que haga el estudio comparado de la llamada renta feudal para averiguar los gradientes de la misma en las distintas áreas. Pero en esa empresa habría ayudado, sin duda, su opinión sobre la integración de la ganadería en el modelo y su traducción en el esquema de la sociedad propuesto. Lo perturbador podría ser, de todas formas, que esa ganadería trashumante, a lo que parece, desde mediados del siglo xIII, ovina en exclusiva, nos llevara a pensar en procesos de comercialización de su lana a escala continental, y con ello nos obligara a plantearnos hasta dónde pueden alargarse, sin romperse, los sucesivos modelos de Feudalismo.

De momento, Villar mantiene las puertas abiertas sin pronunciarse sobre este punto. Como todos los trabajos importantes, el suyo, que constituye el primer intento de abordar en su conjunto la sociedad de la Extremadura castellano-leonesa, interpela no sólo a quienes investigan la historia de esa región, sino, muy concretamente, también a quienes habitualmente lo hacemos sobre las tierras situadas al norte del Duero. Sin reiterar farragosamente la teoría en la que cree, con insistencia abrumadora en las premisas de interpretación, sin referencia explícita a unas conclusiones que se incluyen en aquéllas, el libro de Luis Miguel Villar, como aconteció hace cuatro años con el de Angel Barrios, deja en pie un modelo de organización social presto para su exportación. Hacia Andalucía, desde luego. Pero también hacia el Norte. De ahí el interés de observar sus comportamientos iniciales, su puesta en marcha, tarea que, con enorme convicción en la rotundidad de su paradigma, ha cumplimentado el estudio de Villar. 